\title{
VELEZ DE CORDOVA, PRECURSOR MOQUEGUANO *
}

\author{
Luis Guzmán Palomino
}

\section{PRESENTACION}

Moquegua vio naceren su suelo, probablemente a principio del siglo XVIII, al eminente patriota revolucionario Juan Vélez de Córdova, cuya gesta y sacrificio por la redención de los oprimidos fueron a tal punto meritorios que, en gratitud tal vez tardia, cabe proclamarlo Hijo Predilecto de la Tierra Moqueguana.

Inexplicablemente, la gesta de este Precursor de Precursores es aún poco conocida entre sus coterráneos. Excepto un colegio en Cuajone, no hay plaza, monumento, placa recordatoria, ni siquiera una avenida o calle que honre su nombre. Y esa ingratitud, causada tal vez por grupos opuestos a la vindicación de lo autóctono, creemos que debe repararse sin demora, ya que así lo exige en rigor la verdad histórica. Movidos por tal afán es que ofrecemos estabreve reseña rememorativa, cuya pretensión es motivar mayor interés por un pasado glorioso que es ya tiempo de reivindicar. (José Carlos Vilcapoma).

\section{INTRODUCCION}

Lahistoria del Perúbajo la dominación española es nada más que la historia de como se impuso en el Perú la violencia del estado dominante sobre las mayorías oprimidas, con toda su secuela de explotación, barbarie y muerte. La Colonia -ha escrito Alipio Valencia Vega-fue solamente el sacrificio constante de la raza nativa para cimentar el poderío de los aventureros que en América hicieron sus cuantiosos patrimonios y para cimentar el orgullo de los reyes de España y sus fastuosas cortes. Nada contribuyó a amenguarla servidumbreyesclavitud de los indios. Despojados de sus tierras y de su libertad, costearon con su sangre y su esfuerzo el bienestar y el boato de funcionarios y autoridades yextrajeron metales del seno de las montañas para amos de tierra ajena y monarcas de ultramar. Lágrimas ydolor reinaron durante siglos en los miserables hogares indios, muertes y

\footnotetext{
- El presente artículo apareció en un publicación a mimeógrafo en Huancayo, Perú. Lo difundimos por su interés para la historia regional. (Gentileza del Ing. L. Molina).
}

aniquilamiento fueron los presentes griegos que nos trajeron los conquistadores y "colonizadores" europeos.

Los españoles fueron conscientes de las nefastas consecuencias que causó su presencia en el país que antes viera florecer la gran civilización donde fueron realidad las llamadas utopías de los modernos socialistas. Yhubo incluso un virrey, el Conde de Lemos, que con inocultable sentimiento de culpa escribió entonces: "Cuándo descansa el indio? Cuándo duerme? No hay nación en el mundo tan fatigada. Yo descargo mi conciencia con informar que NO ES PLATA LO QUE SE LLEVA AESPAÑA, SINO SUDOR Y SANGRE DEINDIOS".

Con la dominación española el mundo andino fue desestructurado. No fue ciertamente destruido, primero porque los pobladores nativos pugnaron tenazmente por permitir la supervivencia de sus instituciones, fundamentalmente al interior de sus ayllus, y luego porque los nuevos amosdel Perúadvirtieron quemanteniendoalgunas estructuras inkaikas les sería posible ejercer con menor dificultad la dominación.

Los españoles impusieron bruscamente una cultura totalmente extraña al mundo andino, determinando asi una superposición de dos sectores, uno minoritario pero dominante y el otro mayoritario ydominado. Ambas culturas no vivieron yuxtapuestas, sin vínculos; más bien coexistieron relacionadas, porque -como dice Nathan Wachtel-elsectorespañol sólo pudo sobrevivir extrayendo la sustancia del sector indígena, ejerciendo para ello la violencia como método preponderante.

Sometido por la fuerza a un orden extraño el mundo andino sufrió profundos trastornos, cuyas principales consecuencias fueron la catástrofe demográfica, la crisis moral y la catástrofe socio-económica. No cabe aquí analizar en detalle lo que fue aquella desestructuración; y grosso modo bastará decir que a la progresista y paternal casta de los orejones que rigió el estado socialista inkaiko, sucedióla brutaly depredadora clase dominante española, que resucitando caducas formas feudales y esclavistas europeas condenó a las 
grandes mayorías del Perú a una miseria hasta entonces desconocida. Si en el estado inkaiko hubo coherente relación entre estado y pueblo, pues se respetaron escrupulosamente los principios ancestrales de reciprocidad y redistribución, con la intromisión de los españoles se formaron en el Perú dos mundos diametralmente opuestos; el occidental dominante y el andino dominado; aquel poseedor de todos los derechos, éste sujeto a todos los deberes, iniciándose así para los peruanos la época del caos y la dependencia.

Pero no se crea que el poblador andino soportó indolente la bárbara opresión. Nada más falso que la letra aquella de que "El peruano oprimido largo tiempo en silencio gimió", actitud que sólo atañe a la élite criolla, émula y sucesora de la clase dominante española. Porque valido de diversos mecanismos, el peruano manifestó de continuo su rebeldía ysu ansia de recuperar la autonomía perdida, heroica gesta que tendría su punto culminante en la lucha armada de liberación nacional cuyos máximos representantes fueron los Túpac Amaru.

\section{EL MOVIMIENTO DE LIBERACION INKA : LOS RADI- CALES DEL SIGLO XVIII}

Terminando el primer cuarto del siglo XVIII, la lucha libertaria de los oprimidos cobró auge en el virreinato peruano. Líderes indios y mestizos de sectores radicales decidieron enfrentar a la clase dominante hispano-criolla pasando de la etapa conspirativa a la lucha armada; y estallaron las rebeliones en varias provincias del Centro y Sur del país, citándose como principales las que tuvieron lugaren Oropesa, Azángaro, Cotabambas, Carabaya y Castrovirreina, que fueron todas ahogadas en sangre cuando tiranizaba el Perú el virrey Marqués de Castellfuerte.

Indudablemente, esa lucha se inscribia en el Movimiento de Liberación Inka, cuyos comandos, de momento, no fueron visibles. La mayoría de éstos, al parecer, no consideraba todavía oportuno desatar la guerra revolucionaria en vasta escala; $y$, contando con el apoyo de mestizos aculturados e intelectuales criollos de avanzada, bregaba más bien por aliviar la suerte de los oprimidos recurriendo a la "justicia" española. Consideraba que no se había agotado esa vía y constantemente remitía denuncias ante la corte, enviando incluso secretos comisionados para que abogaran personalmente porlos esclavizados indios. Se resistían a admitir que se habían convertido en letra muerta las miles de páginas de la famosa legislación indiana que prohibía excesos yabusos; y amparándose en ellas repetían quejas sin reparar en que lapropia coronalas desestimariaporque precisamente a través de la inicua explotación de los indios era que conseguía proveer sus arcas harto mermadas por las continuas guerras que sostenía con otros Estados europeos.

Desoídas las denuncias, burlados los comisionados, varios grupos de indios y mestizos tendieron a radicalizarse, e iniciaron -o precipitaron- la lucha focalizada, pensando que a través del ejemplo conseguirían sublevar todo el país.

Hubo entonces asalto, saqueo y a veces destrucción de haciendas, obrajes y minas; desacato a mandones e incluso ajusticiamiento de curas y corregidores, como respuestas desesperadas a la violencia ejercida por los opresores con sus mitas, tributos y trabajos forzados. Y, a la vez, se adelantaron proyectos serios que apuntaban a la restauración del estado autónomo a través de la guerra de liberación nacional. La figura del Inka y el ideal mesiánico fueron entonces propagandizados de uno a otro confín del país, pero los líderes radicales actuaron por propia iniciativa y descoordinadamente. Uno de ellos, Juan Santos Atahuallpa Apu Inka, llegó incluso a la conclusión de que en la sierra no se daban aún las condiciones necesarias para el inicio de la revolución con expectativas de triunfo; y se internó entonces en la región selvática, sabedor de que en ella se libraba por ese tiempo una tenaz lucha de resistencia nativa contra la dominación extranjera.

Otros de esos radicales, el principal sin duda por el contenido ideológico de su proyecto revolucionario fue Juan Vélez de Córdova.

\section{ELCONSPIRADORMOQUEGUANO}

Probablemente de origen aymara collavino, Juan Vélez de Córdova nació en las serranías de Moquegua, a principios del siglo XVIII, racialmente mestizo pero culturalmente indio, ya que se proclamó Inka descendiente de Huáscar al momento de emprender su lucha libertaria.

Pasó su niñez y adolescencia en Moquegua, trasladándose luego al Alto Perú donde apreció en carne viva el sufrimiento de los indios esclavizados en minas, obrajes y haciendas, tiranizados por corregidores, hacendados y curas, ofreciendo sudor y sangre en trabajos forzados, sometidos, en fin, a la más cruel dominación y exterminados en verdadero genocidio.

Buscó entonces contacto con los líderes del Movimiento de Liberación Inka, hallando especial acogida en Eugenio Pachamir, curaca de Oruro. Con ese apoyo conformó un núcleo revolucionario, al que se agregaron en calidad de líderes Miguel y Ramón de Castro.

Elproyecto libertario fue preparado secretamen- 
te, con una labor proselitista que exigió varios años de continuo trajinar. Desde la base altoperuana, Vélez de Córdova se trasladaría a diversas provincias del sur, poniéndose en inteligencia con líderes indios y mestizos $\mathrm{e}$ inclusive buscando apoyo entre criollos pobres descontentos con el régimen colonial. En la costa del Pacífico obtuvo promesa de apoyo de varios curacas, principalmente en su tierra moqueguana; y pasóluego al Cuzco con intención de ganar para la revolución a Juan Bustamante Carlos Inka, considerado entonces el más representativo descendiente del linaje imperial inkaiko. Infortunadamente, no pudo conseguir la adhesión del cuzqueño, quien incluso procuró hacerle ver que la coyuntura no se presentaba favorable para un levantamiento en vasta escala. No obstante, las tratativas con el Inka se repetirían, existiendo pruebas documentales de que la relación se mantuvo entre 1734 y 1737 , por lo menos.

Además según sospecha Boleslao Lewin Vélez de Córdova habría buscado un entendimiento con el grupo de intelectuales criollos que conspiraba en Lima a favor de la causa inkaika, Precisamente notando la actitud de esa minoría progresista fue que concibió la idea de un frente amplio de sectores opuestos a la dominación de los guampos-como tildaban a los españoles-, resultando así precursor del proyecto que cuarenta años más tarde defendería infructuosamente José Gabriel Túpac Amaru.

Y, como hombre de sólida cultura, conocedor de lo que acontecía a nivel mundial, no puede descartarse que tomara también contacto con agentes extranjeros interesados en crear problemas a España, como los ingleses y portugueses que actuaban secretamente en varias ciudades del virreinato. Algo similar realizaría Juan Santos Atahuallpa, si es que no visitó personalmente el Viejo Mundo, como mencionan algunas crónicas.

\section{EL MANIFIESTO DE AGRAVIOS DE 1739}

Culminado el trabajo proselitista, Vélez de Córdova redactó en Oruro un célebre "Manifiesto de Agravios", trascendental documento que quiso ser justificativo de la lucha revolucionaria cuyo inicio fue fijado para el 8 de julio de 1739.

Dirigió el "Manifiesto" a indios ycriollos, considerando que los primeros habían sido reducidos a una condición peor que la esclavitud no obstante ser "legítimos señores de la tierra", y prometiendo a los segundos que serían "empleados en las conveniencias del reino según se mostrasen fieles".

Hubo, evidentemente, recelo respecto a la posibilidad de que los criollos aceptasen ser parte en una radical transformación del país; de alli que el documento deslizase una velada amenaza pues la revolución sólo respetaría a los que acatasen un Perú gobernado por Inkas. De modo que el acercamiento a los criollos fue más bien táctico, pues Vélez de Córdova debió advertir que la mayoría de los conformantes de ese sector social se hallaba hermanada con los españoles, no sólo por lazos raciales, sino porque usufructuaba con ellos del poder y vivía a costa de indios y mestizos. Lo que pretendió ellíder moqueguano fue aprovecharel momentáneo descontento de los criollos, luego que el gobierno colonial intentó comprenderlos entre los tributarios. Y, en todo caso, el mensaje fue para los criollos pobres, que en el Alto Perú no eran pocos.

Respecto a los indios, el "Manifiesto" describió con patetismo la situación de miseria a la que habían sido reducidos: "Los españoles tienen tan oprimidos a los pobres naturales que fuera de pagar tan crecidos tributos anualmente, los precisan a que personalmente concurran a mitar en los minerales de Potosí y Huancavelica todos los años, sobre diez mil a cada uno de estos minerales, que resulta que estos miserables no gozan de la vida, de sus mujeres, de sus haciendas ni de sus ganados, porque violentados se ven precisados a dejarlo todo, $y$ muriendo los más en tan rígidos destemples quedan los pobres hijos huérfanos, las miserables mujeres viudas, sus ganados perdidos, las casas desamparadas y los pueblos destruidos".

El ideal de la restauración del Imperio de los Inkas, para reparar el trastorno causado por la presencia de los extranjeros, se patentizó con meridiana claridad en el documento. Vélez de Córdova hizo una dura crítica de los invasores que jefaturados por Pizarro asesinaron a los reyes Inkas, usurpando 'no sólo las vidas, sino todas las tierras". Exigió por ello la recomposición, la vuelta al orden antecedente: "Miúnica intención-dijo-(es) restablecer el Gran Imperio y Monarquía de nuestros reyes antiguos".

Así, pues, desde un principio Vélez de Córdova proclamó el separatismo: no hubo aquí la vacilación calculada o ingenua que se apreciaríaluego en la primera fase de la revolución de los Túpac Amaru. La cuestión en 1739 era arrasar con todos los guampos o chapetones, yderribar sus instituciones para restablecer el Imperio de los Inkas cuyo primer acto de gobierno suponia la abolición de tributos y mitas onerosos y el exterminio de corregidores con la consecuente reivindicación de los oprimidos.

"Hallándose en el presente y entre nosotros -decía el documento- uno de la real sangre de nuestros Inkas del gran Cuzco en quinto grado de parentesco y con deseo de restaurar lo propio y volver a establecer esta monar- 
quía, se suplica a los criollos y a los caciques y a todos los naturales le den la mano para esta tan heroica acción de restaurar lo propio y libertar la patria purgándola de la tiranía de los guampos que nos consumen..., librando a los naturales de tributos y mitas para que gocen en quietud lo que Dios les dio y alcen con lo que tienen de repartimientos de los corregidores, cuyo nombre tirano se procurará borrar de nuestra república"

El "Manifiesto" pusoal descubiertola farsa de las Audiencias, cuyos miembros lejos de hacer justicia favorecian 'la sinrazón por sus intereses". En esto, Vélez de Córdova se manifestó más radical que Túpac Amaru, pues no se forjó esperanza alguna en ninguna institución colonial. Para el moqueguano no había españoles buenos, porque entre ellos -dijo- "más honrado era el que más tiranías y robos perpetraba".

Finalmente, Vélez de Córdova quiso estimulara los vacilantes trayendo a colación que en el momento era propicio para desatar la revolución, pues hallándose España en guerra con Portugal e Inglaterra le sería difícil socorrer al virreinato.

\section{EPILOGO}

Por desgracia, no faltó entre los conjurados un renegado que delató la trama a las autoridades coloniales. Ese traidor se llamó Bernardino Ojeda, cuya denuncia permitió la captura de los patriotas un par de dias antes del fijado para el estallido de la revolución.

Aparte de la prisión de los principales líderes, la región fue "pacificada" con violentas represiones. Y poco después, tras una farsa de juicio, Vélez de Córdova fue ejecutado, acompañándolo en su glorioso holocausto Eugenio Pachimir, Ramón de Castro, Tomás Agudo y Miguel de Castro.

No negó el líder moqueguano su responsabilidad en la autoría del "Manifiesto de Agravios", ni su calidad de conductor revolucionario, aún a sabiendas de que en ello se le iba la vida.

A decirverdad, los españoles no pudieron matarlo, pues al cumplirse la bárbara condena contra él pronunciada. Vélez de Córdova habia ya nacido para la inmortalidad.

\section{ANEXO No. 1}

\section{EL “MANIFIESTO DE AGRAVIOS” DE 1739}

Manifiesto en que se hacen patentes las razones que asisten a los criollos ilustres de estos nuestros reinos delPerú, así españoles (americanos) como pobres indios y naturales, que siendo legítimos señores de la tierra unos y otros; nos vemos oprimidos de la tirania,

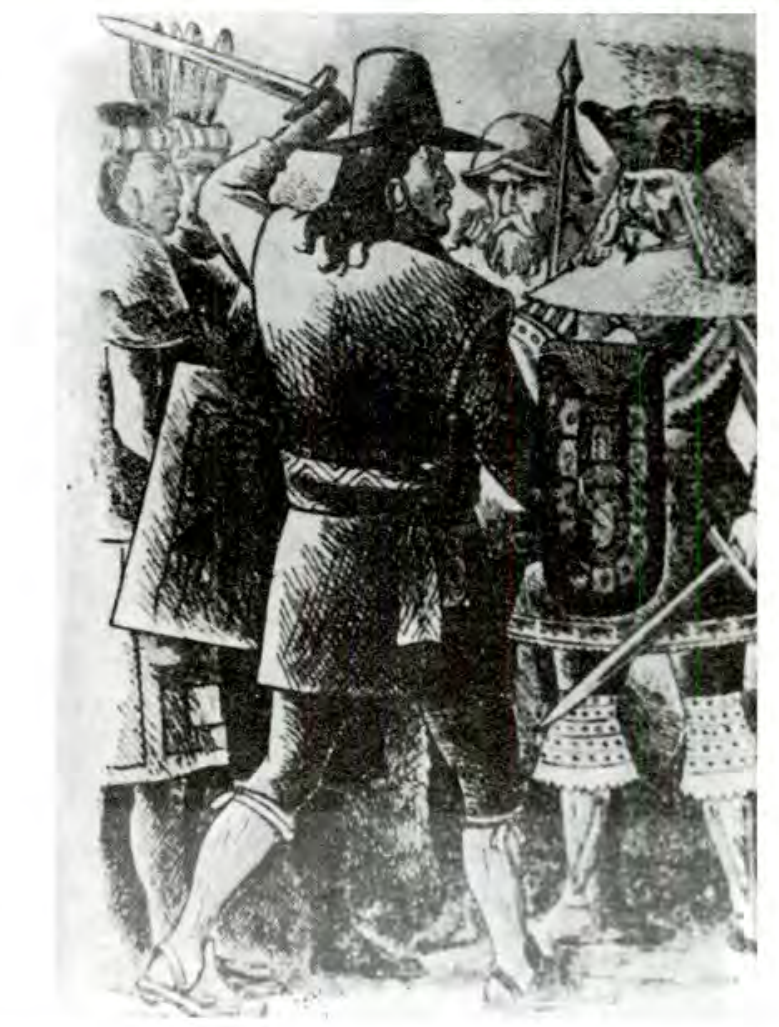

viviendo con sobresalto y tratados poco menos que esclavos, por lo cual, y por ver si pueden salir de tamaño cautiverio se proponen las razones siguientes para forzar los ánimos y que sacudan el yugo de sus cervices, siendo los puntos los que siguen:

$1^{\circ}$ Sabido es cómo el Pontífice Alejandro VI dio permiso a los Reyes de Castilla para que sembrasen la semilla del Santo Evangelio en estos reinos, convirtiendo al (ilegible) de la Santa Madre la infidelidad. Y pasados los españoles a él, se convirtieron por su codicia a la tiranía, degollando a los reyes y naturales de ellos, usurpándoles no sólo las vidas sino todos sus haberes $y$ tierras con cuanto éstas fructifican.

$2^{\circ}$ No contentos dichos españoles con lo arriba dicho, tienen tan oprimidos a los pobres naturales que fuera de pagar tan crecidos tributos anualmente los precisan a que personalmente ocurran a mitar en los minerales de Potosi y Huancavelica todos los años sobre diez mil indios a cada uno de estos minerales que resulta que estos miserables no gozan de la vida, de sus mujeres, de sus haciendas ni ganados, porque violentados se ven precisados a dejarlo todo, ymuriendo los más en tan rígidos destemples, quedan los pobres hijos huérfanos, las miserables mujeres viudas, sus ganados perdidos,, las casas desamparadas y los pueblos destruidos.

$3^{\circ} \mathrm{A}$ que se agrega que pasando a estas nuestras tierras los ampos (sic) sin más que sus cuerpos, nos usurpan de tal modo que nos chupan la sangre, dejándonos tan 
desustanciados que solo nos queda la boca para quejarnos, siendo entre ellos más honrado el que más roba y más tiranías ejecuta; y como el recurso se ve tan lejos y las Audiencias superiores que debian amparar al desvalido no sólo no lo hacen, sino antes favorecen la sinrazón por sus intereses, gime yllora el pobre sin recursos ni remedio humano.

$4^{\circ} Y$ para verificar todo lo dicho véase cuántos arbitrios se dancadadianuevamente parasacardineroyaqueriendo empadronara los criollos y mestizos para que paguen tributo, como se vio en Cochabamba, pues porque los criollos se opusieron a tan injusta pretensión hubo horcas, muertes y destrucción del pobre, con mofa y escarnio que hicieron y cada día hacen los de España de los Criollos, tratándolos con vilipendio y desprecio, como se vio en el donativo que se acaba de exigir, el que se quedará entablado perpetuamente por tributo, si los señores criollos no lo reparan a tiempo, siendo el que se ofrece el más a propósito que se pueda discurrir; siendo sus razones las que siguen, que el autor pide se lean con algún cuidado por los señores criollos y pornuestros caciques yhermanos, para que se esfuercen a procurar por los medios posibles la amada libertad que asílo esperamos; siendola primera:

1a. Hallándose en la presente yentre nosotros uno de la real sangre de nuestros Inkas del gran Cuzco en quinto grado de parentesco ycon deseo de restaurar lo propio y volvera establecer la monarquía, se suplica a los criollos y a los caciques y a todos los naturales le den la mano para esta tan heroica acción de restaurar lo propio y libertar la patria purgándola de la tiranía de los guampos que nos consumen y cada día va a más nuestra ruina.

2a. Promete a los criollos españoles emplearlos en las conveniencias del Reino según se mostrasen fieles y a los caciques honrarlos como es de razón por los señores de la tierra, adelantándolos en conveniencias, librando a los naturales de tributos y mitas para que gocen en quietud lo que Dios les dio y se alcen con lo que tienen recibido de repartimientos de los corregidores, cuyo nombre tirano se procurará borrar de nuestra república.

3a. Se ofrece la presente para intentar esta empresa el motivo de hallarse el Rey de España en guerra con Portugal e Inglaterra, por lo que mira a la Europa, y en este reino los navíos embarazados en los empleos y la Armada de Portobeloy por eso sin gente ni armas en Lima, siendo esta ocasión la más a propósito que imaginarse pueda. Y así Señores Criollos y Hermanos yqueridos Caciques y mis amados naturales, manos a la obra que de parte tenemos la justicia y el favor de Dios Nuestro
Señor que nos ha de amparar en tan justa demanda, protestando a todos y cada uno de por sí, que nunca es ni será mi intención oponerme a la santísima ley de Nuestro Señor Jesucristo, ni apartarme, ni permitir se aparte ninguno del gremio de la Santa Iglesia, antes sí procurar cuando fuere de mi parte el aumento de ella, no permitiendo se profanen los templos de Dios ni las casas Sagradas, antes sí venerarlas como ellas'se merecen y los cristianos tenemos la obligación, siendo mi única intención restablecer el Gran Imperio y Monarquía de nuestros reyes antiguos, reservando para la vista de cada uno de los nuestros otras muchas razones que no se pueden fiar de la pluma, previniendo a nuestros hermanos que serán todos bien tratados y pagados anticipadamente, que yo quedaré con la gloria de haberlos librado a todos de tanta tiranía; no se firma este papel por excusar riesgos, podrán nuestros criollos darle asentimiento y creer a quien lo lleva, que es de los nuestros, Dios los guarde y les de el esfuerzo que deseo con todos aciertos.

\section{ANEXO NRO. 2}

DOCUMENTOS EN EL ARCHIVO GENERAL DE INDIAS, REFERENTES A LAS SUBLEVACIONES DE 1739

\section{A.C.I. CHARCAS 363 Ficha Nro. 1}

Audiencia de Charcas.

Expediente sobre la sublevación de Oruro, castigo de los delincuentes y demás incidentes.

\section{A.G.I. CHARCAS 363 Ficha Nro. 2}

$$
\text { Año : } 1739
$$

Doc. Nro. 1

Varios documentos referentes a la sublevación de Oruro.

1. Relación de Martín Espeleta y Villanueva. Este documento contiene.

- 2 sentencias.

- Manifiesto con 7 razones

- 1 bando

2. Relación de D Martín Espeleta y Villanueva de los reos complicados en la sublevación de Oruro, el castigo y prisión de los delincuentes.

\section{A.G.I. Charcas 363 Ficha Nro. 3}

Año: 1739

Doc. Nro. 2

El presidente de la Real Audiencia, D. Antonio 
Hermenegildo de Quesefan y Molinedo, reunido con todos los componentes de la Real Audiencia, pide a todos los corregidores de las distintas provincias presten la necesaria ayuda para sofocar la sublevación de Oruro, el castigo y prisión de los delincuentes. Contiene:

- 11 cartas a los distintos corregidores.

- Manifiesto con 7 preguntas.

- 2 bandos en que se pide que todos los hombres se presenten con sus armas ante el capitán de sentencias.

\section{A.G.I. CHARCAS 363 Ficha Nro. 4}

Año : 1739

Doc. Nro. 3

Testimonios de los autos obrados en la Audiencia de la Planta contra Gabriel de Santa María, vecino de Vallegrande, jurisdicción de Santa Cruz, a quien se le ha imputado ser uno de los reos comprendidos en el delito de Rebelión intentado en la villa de Oruro.

Este documento contiene:

- 8 declaraciones

- 4 cartas

- 1 petición

- Investigación en torno a Gabriel de Santa María y su compañeroTomás Agudo.

- 8 declaraciones por 8 testigos.

- 1 sentencia; absolver a Gabriel de Santa María al Presidente de la Audiencia.

\section{A.G.I. CHARCAS 363 Ficha Nro. 5}

Año : 1739

Doc. Nro. 4

Expediente perteneciente a la villa de Oruro, pacificada por el corregidor de ella, D. Martín de Espeleta y Villanueva.

Contiene:

- Relación del Cabildo Eclesiástico.

- Relación del Cabildo Secular.

- 2 cartas de D. Martín de Espeleta y Villanueva.

- Varias cartas de la Audiencia de Charcas a S.M. dando cuenta de la sublevación de Oruro y de los méritos de D. Martín de Espeleta que apaciguó la sublevación y de los castigos de los delincuentes. La relación data de los años: 171, 1742, 1743.

\section{A.G.I. CHARCAS 363 Ficha Nro. 6}

Doc. Nro. 5

El presidente de la Real Audiencia de la Plata informa de la sublevación intentada poralgunos de los vecinos de la Villa de Oruro yel testimonio de los autos que hasta el presente se habían obrado.

\section{A.G.I. CHARCAS 363 Ficha Nro. 7}

Año: 1739

Doc. Nro. 6

Testimonio de los autos obrados en la Villa de Oruro y la Real Audiencia de la Plata. La averiguación y castigo de los reos comprendidos en el delito de rebelión intentada en otra Villa de Oruro.

Este cuaderno contiene:

- 3 cartas al vicario providencial

- 5 cartas a D. Martín de Espeleta y Villanueva.

- 3 cartas más.

- 1 interrogatorio. Fecha de 1739. 7 preguntas, 125 testigos.

\section{A.G.I. CHARCAS 363 Ficha Nro. 8}

Año: 1739

Doc. Nro. 7

Testimonio de los autos obrados en la Real Audiencia de la Plata sobre el castigo y averiguación de los reos comprendidos en el delito de rebelión intentada en la Villa de Oruro.

Este cuaderno contiene:

- cartas:

- 13 a los corregidores

- 20 a D. Martín de Espeleta y V.

- 10 al presidente de la Real Audiencia

- 10 cartas más, sueltas

- Manifiesto con 6 razones en las que los indios indican la opresión a que se hallan sometidos.

- Bandos en número de 5

- Declaración con 24 testigos

- 1 sentencia

- Confesión de Tomás Agudo: 26 preguntas y 26 respuestas.

- Confesión de Ramón de Castro: 26 preguntas y 26 respuestas.

- 2da. confesión de Tomás Agudo: 26 preguntas y 26 respuestas.

- Decreto de Proseguimiento: condena.

- Interrogatorio: Fecha 1739. 10 interrogatorios: 62 preguntas y 62 respuestas.

- 2 peticiones del abogado de Ramón de Castro.

- 1 petición del abogado de Tomás Agudo.

- 8 peticiones del Fiscal de la Real Audiencia.

- 1 petición del Procurador de la Real Audiencia.

- Ratificación de Ramón de Castro.

\section{A.G.I. CHARCAS 363 Ficha Nro. 9}

Año: 1739

Doc. Nro. 8

- Ratificación de Tomás Agudo.

- Sentencia: pena de muerte a Tomás Agudo. 
- Ejecución de la pena de muerte a Tomás Agudo.

- 1 real Provisión.

- 2 declaraciones con 5 preguntas cada una.

- Sentencia: pena de muerte a Ramón de Castro.

- Ejecución de la sentencia a Ramón de Castro.

- Relación de pagos: 405 pesos

- Relación de bienes:

1 escopeta

1 puñal

2 lomillos

2 capas

\section{BIBLIOGRAFIA}

Boleslao Lewin, La rebelión de Túpac Amaru y los orígenes de la Independencia de Hispanoamérica, Buenos Aires, 1967

Juan José Vega Historia General del Ejército Peruano-Dominación Española del Perú, Lima, 1981.

Marcos Beltrán Avila, Capítulos de la historia colonial de Oruro, La Paz 1925.

Alipio Valencia Vega, Julián Tupaj Katari, caudillo de la Liberación India, Buenos Aires, 1950.

Pablo Macera, Nuestra historia, el indio y sus intérpretes peruanos del siglo XVIII, en Cultura y Pueblo, Año I.

Miguel Marticorena Estrada, ...........co y restitución en Tupac Amaru. Lima, 1981. (llegible en el original)

Horacio Villanueva, La idea de los Inkas como factor favorable a la independencia, Cuzco, 1958.

Atilio Sivirichi, Túpac Catari, Virrey de Túpac Amaru, Lima 1981.

Fernando Cajías, Repercusiones de la Revolución tupamarista en la villa de Oruro y Comarcas aldeañas, Lima, 1982.

Edmundno Guillén, La acción de Túpac Amaru; obje-

\section{1 peso y 18 reales}

2 mulas

(Extracto del trabajo sobre Documentos en el Archivo General de Indias referentes a sublevaciones indígenas en el siglo XVIII (Perú, Bolivia, Argentina y Chile), presentado porFrancisco Morales Padrón (España) al Quinto Congreso Internacional de Historia de América realizada en Lima del 31 de julio -6 de agosto de 1971).

tivo; la reconquista de la soberanía del Perú, Lima, 1982

Carlos Daniel Valcárcel, Rebeliones Indígenas, Lima 1946.

Rubén Vargas Ugarte, Historia General del Perú, Lima, 1971.

Clemente Robert Markham, Historia de Perú, Lima, 1941.

John Rowe, El movimiento nacional Inka del siglo XVIII, Cuzco, 1954.

Luis Durand Flores, Independencia e integración en el Plan político de Túpac Amaru, Lima, 1973.

Scarlett O'Phelan Godoy, Túpac Amaru y las sublevaciones del siglo XVIII, Lima, 1967.

Manuel de Mendiburu, Diccionario Histórico-Biográfico del Perú, Lima, 1931.

Guido Delran, Historia Rural del Perú, Lima, 1981.

Nathan Wachtel, La visión de los vencidos, París, 1971.

Karen Spalding, De indio a campesino, Lima, 1974.

Guillermo Lohmann Villenas, Los ministros de la Audiencia de Lima, Sevilla, 1974. 